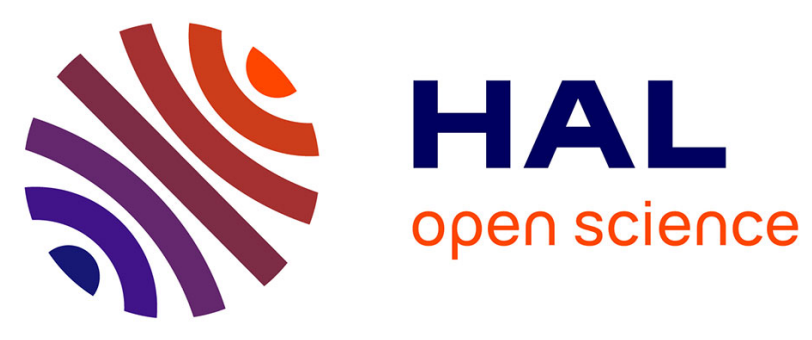

\title{
Information Fusion With Belief Functions for Detection of Interturn Short-Circuit Faults in Electrical Machines Using External Flux Sensors
}

Miftah Irhoumah, Rémus Pusca, Eric Lefevre, David Mercier, Raphaël Romary, Cristian Demian

\section{To cite this version:}

Miftah Irhoumah, Rémus Pusca, Eric Lefevre, David Mercier, Raphaël Romary, et al.. Information Fusion With Belief Functions for Detection of Interturn Short-Circuit Faults in Electrical Machines Using External Flux Sensors. IEEE Transactions on Industrial Electronics, 2017, 65 (3), pp.2642-2652. 10.1109/TIE.2017.2745408 . hal-03354093

\section{HAL Id: hal-03354093 https://hal.science/hal-03354093}

Submitted on 24 Sep 2021

HAL is a multi-disciplinary open access archive for the deposit and dissemination of scientific research documents, whether they are published or not. The documents may come from teaching and research institutions in France or abroad, or from public or private research centers.
L'archive ouverte pluridisciplinaire HAL, est destinée au dépôt et à la diffusion de documents scientifiques de niveau recherche, publiés ou non, émanant des établissements d'enseignement et de recherche français ou étrangers, des laboratoires publics ou privés. 


\title{
Information fusion with belief functions for detection of inter-turn short-circuit faults in electrical machines using external flux sensors
}

\author{
Miftah Irhoumah, Remus Pusca, Eric Lefevre, David Mercier, Raphael Romary, Member, \\ IEEE, Cristian Demian
}

\begin{abstract}
This paper proposes a diagnosis method which exploits the information delivered by external flux sensors placed in the vicinity of rotating electrical machines, in order to detect a stator inter-turn short circuit. This fault induces a dissymmetry in the external magnetic field that can be measured by the sensors. Sensitive harmonics are extracted from the signals delivered by a pair of sensors placed at $180^{\circ}$ from each other around the machine and data obtained for several sensor positions are analyzed by fusion techniques using the belief function theory. The diagnosis method is applied on induction and synchronous machines with artificial stator faults. It will be shown that one can obtain high probability to detect the fault using the proposed fusion technique: on various series of measurements, the proposed approach has obtained a $90 \%$ detection rate on a considered machine.
\end{abstract}

Keywords - inter-turn short circuit fault, flux sensor, induction machine, diagnosis, external magnetic field, belief functions.

\section{INTRODUCTION}

$\mathrm{M}$ onitoring of rotating electrical machines still remains an essential point of reliability and operational safety of electrical systems [1,2]. With tolerant control $[3,4]$ it has been the interest of many researches during the last decades. Therefore, studies on fault detection and diagnosis of electrical machines are nowadays a very important issue, particularly regarding induction machines as these machines are widely used in industry [5]. In this context, many researches have been focused on the detection of stator inter-turn short circuit fault in induction machines due to the fact that approximately $30-40 \%$ of the induction motors faults fall into the category of stator winding related faults [6]. Stator current is the most common variable used to detect the stator inter-turn short circuit fault [7-10], and other faults [11,12]. Methods using internal flux probe have been developed [13-15] but they are

Manuscript received November 18, 2016; accepted July 27, 2017. Miftah Irhouma, Remus Pusca, Raphael Romary and Cristian Demian are with the Univ. Artois, EA 4025 LSEE, F-62400, Béthune, France. (e-mail: raphael.romary@univ-artois.fr - corresponding author)

Eric Lefevre and David Mercier are with Univ. Artois, EA 3926 LGI2A, F-62400, Béthune, France. invasive methods, what limits their use. More recently, methods based on the exploitation of the external magnetic field have been developed [16-22]. These methods use an external flux sensor and they present as main advantages to be fully non invasive, inexpensive, and easy to implement. However, these methods suffer of a lack of confidence from machinery operators in industry.

In previous works, the detection of inter-turn short circuits in the stator windings of electrical machines has been shown possible by measuring a harmonic value of the magnetic field around the machine [23]. The study shows that the slotting harmonics are sensitive to this fault, more than these ones measured in the current spectrum.

Recently, a method based on two flux sensors has been developed [24]. Two sensors being positioned at 180 degrees with respect to each other, the method analyses the behaviors of the sensitive harmonics measured by each sensor when the load varies. The main advantage of this method is that it does not require the knowledge of the healthy state because the decision is not tied to a comparison with a healthy signature. However the effectiveness of the method depends on the position of the flux sensors relatively to the faulty winding.

In order to improve the fault detection, diagnosis methods generally use techniques such as parameter estimation [25], artificial neural networks [26,27], fuzzy logic [28,29], wavelet [30,31], complex vector [32], Support Vector Machine (SVM) [33], Artificial Ant Clustering techniques [34] or pattern recognition [35,15]. More recently, data-based techniques and multivariate statistical methods have shown to be a promising approach for industrial process diagnosis [36][37]. All these techniques give good results concerning the classification of the state of the machine, but they need a learning stage for classification of the state of the machine, or a model of the machine, or advanced signal processing techniques. Other techniques using information fusion have been exploited for diagnosis of transformers [38], wind turbines [39], but also for diagnosis of bearing faults [40], rotor faults [41], or stator faults [42] in electrical rotating machines. These techniques enable the improvement of the decision-making process when several pieces of information are available. Each piece of information brings a part of the true value taken by a variable. Applied to electrical machines, these techniques generally use 
vibrations or currents as exploited variables but none of them use the external magnetic field.

The proposed paper presents an original method that performs measurements of external flux density at several positions around the machine. Each measurement constitutes a piece of information regarding the presence of a fault. Fusion technique using belief functions [43] is then used as a frame to represent and combine information to make a final decision concerning the question of the presence of a fault in the winding of the machine tested.

This paper is organized as follows. In Section II, theoretical basis about sensitive harmonics in the external magnetic field spectrum are exposed, as well as the principle with 2 flux sensors. Then, in Section III, basic concepts on belief function theory are introduced. The application of the proposed method to detect a fault is exposed in Section IV and tested in Section $\mathrm{V}$, where it is shown that one can obtain high probability of fault detection in an induction machine or in a synchronous machine by using it.

\section{ANALYTICAL MODELING}

\section{A. Air-gap and external flux density}

Analytical developments that lead to define the air-gap flux density and the external magnetic field are described in $[23,24]$. This section recalls the main results obtained from a three-phase induction machine. The modeling of the machine will consider the following parameters and notation:

$p$ : pole pair number.

$N,{ }^{s} N^{r}$ : number of stator slots and rotor bars per pole pair.

$\omega$ : angular frequency of the sine supply voltage $(=2 \pi \mathrm{f})$.

$b$ : air-gap flux density of the healthy machine.

$b_{s c}$ : air-gap flux density generated by the fault.

$\mathcal{E}$ : air-gap magnetomotive force

$\lambda$ : per area unit air-gap permeance.

$s$ : slip of the machine.

It is assumed that the stator is supplied by a three phase balanced sinusoidal voltage system of $\omega$ angular frequency. As far as the magnetic reaction of the rotor is concerned, it is supposed that the $b$ air-gap flux density content does not change in load. Consequently, only the components generated by the stator energized by the sinusoidal no load currents are considered. $b$ is obtained by multiplying the $\varepsilon^{s}$ air-gap magnetomotive force ( $\mathrm{mmf}$ ) generated by the stator winding by the $\lambda$ per area unit air-gap permeance which takes the slotting effect into account. It is shown that the air-gap flux density can be expressed as follows:

$$
b=\sum_{K, H} b_{K, H}
$$

With:

$$
b_{K, H}=\hat{b}_{K, H} \cos \left(K \omega t-H \alpha^{s}-\varphi_{K, H}\right)
$$

Where $K$ is the frequency rank and $H$ is the pole pair number of a flux density component. $\alpha^{\mathrm{s}}$ is the angular abscissa of any point in the air-gap related to the stator referential $d^{s}$, tied to the phase 1 axis. $\varphi_{K, H}$ is a phase angle.
For a healthy machine $K$ and $H$ are defined as:

$$
\left.\begin{array}{l}
K=1+k r N^{r}(1-s) \\
H=p\left(h^{s}+k s N^{s}+k r N^{r}\right)
\end{array}\right\}
$$

Where $h^{s}$ is the mmf rank that takes all the values defined by: $h^{s}=6 \mathrm{k}+1$ ( $\mathrm{k}$ varies between $-\infty$ to $+\infty$ ). $k s$ and $k r$ are permeance ranks, they are positive, negative or null integers.

In case of a stator inter-turn short circuit fault, additional flux density $b_{s c}$ appears.

$b_{s c}=\sum_{K_{s c}, H_{s c}} \hat{b}_{s c K_{s c}, H_{s c}} \cos \left(K_{s c} \omega t-H_{s c} \alpha^{s}-\varphi_{s c, K_{s c}, H_{s c}}\right)$

With:

$$
\left.\begin{array}{l}
K_{s c}=1+k r^{\prime} N^{r}(1-s) \\
H_{s c}=h+p\left(k s^{\prime} N^{s}+k r^{\prime} N^{r}\right)
\end{array}\right\}
$$

$k s^{\prime}$ and $k r$ ' are equivalent to $k s$ and $k r$, they vary from $-\infty$ to + $\infty$. $h$ is a non-null relative integer, which can take consequently all the values of $h^{s}$.

Considering the values that can be taken by $K$ given by Eq. (1) and $K_{s c}$ by Eq. (3), it results that $K_{s c}$ does not bring new frequencies. This makes the diagnosis by analysis of the changes in the amplitudes of the measured components difficult.

The external flux density considered in this study is supposed to be the transverse field, image of the air-gap flux density $b$ attenuated by the stator magnetic circuit. It is shown that the more $H$ increases, the more the components are attenuated [44]. Therefore, as $H_{s c}$ can especially be equal to \pm 1 , the corresponding faulty components will be weakly attenuated by the stator iron.

\section{B. Diagnosis method}

The method presented in the paper used two flux sensors positioned at 180 degrees with respect to each other, at $\mathrm{x}$ radius from the machine axis as shown in Fig. 1.

Then, the behavior of the sensitive harmonics measured by each sensor, when the load varies, is analyzed. These sensitive components are obtained from Eqs. (2) and (3) for $k r=k r^{\prime}=1$ , and for $H$ and $H_{S C}$ the lower as possible to be weakly attenuated by the stator frame.

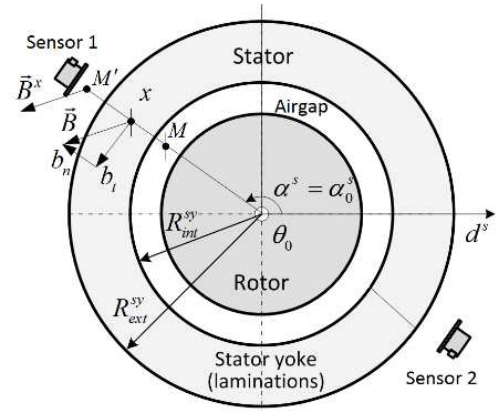

Fig. 1. Simplified geometry of the machine 
As far as $K$ rank flux density harmonics are considered in the external magnetic field, the harmonic $b_{K}^{x}$ relative to the healthy machine and the harmonic $b_{s c, K_{s c}}^{x}$ relative to the faulty machine will merge together to generate the resulting harmonic flux density $b_{K}^{* x}$. For sensor 1 and sensor 2 , this quantity can be expressed as follows:

Sens. $1: b_{K}^{* x 1}=\hat{b}_{K}^{x} \cos \left(K \omega t-\varphi_{K}^{x}\right)+\hat{b}_{s c, K_{s c}}^{x} \cos \left(K_{s c} \omega t-\varphi_{s c, K_{s c}}^{x}\right)(4)$

Sens. $2: b_{K}^{* x 2}=\hat{b}_{K}^{x} \cos \left(K \omega t-\varphi_{K}^{x}\right)-\hat{b}_{s c, K_{s c}}^{x} \cos \left(K_{s c} \omega t-\varphi_{s c, K_{s c}}^{x}\right)(5)$

The only change between Sens. 1 and Sens. 2 is the change of the sign of the faulty term. This is due to the polarity $H_{S C}=1$ that changes the sign of the $\operatorname{cosine}(\cos (\gamma+\pi)=-$ $\cos (\gamma))$, whereas to polarity $H=2$ of the healthy term does not change the sign: $(\cos (\gamma+2 \pi)=\cos (\gamma))$. Consequently in faulty conditions, the magnitude of the component at $K \omega$ angular frequency measured by sensor 1 and sensor 2 will not evolve similarly with the load and possibly in opposed directions. In healthy condition, the term $b_{s c, K_{s c}}^{x}$ is null and when the machine is loaded, the air-gap flux density stays practically identical to that obtained at no load. As theoretically, the external elements responsible for the attenuation act in the same way around the machine for the noload and for the load tests, the amplitudes $\hat{b}_{K}^{* x 1}$ and $\hat{b}_{K}^{* x 2}$ keep similar values or at least evolve in the same way when the load changes in healthy conditions. Fig. 2 shows the variations of $\hat{b}_{K}^{* x 1}$ and $\hat{b}_{K}^{* x 2}$ for a 4-pole induction machine with $N^{r}=16$ that corresponds to a $850 \mathrm{~Hz}$ sensitive harmonic (practically, this frequency can move with the slip $s$, but will be identified as being the harmonic at $850 \mathrm{~Hz}$ ). It can be observed that both quantities evolve in the same direction with the load in healthy condition and in opposite direction in faulty condition. Therefore, difference of variation of the magnitude $\hat{b}_{K}^{* x}$ of sensors 1 and 2 is a good indicator of an inter-turn short circuit fault.

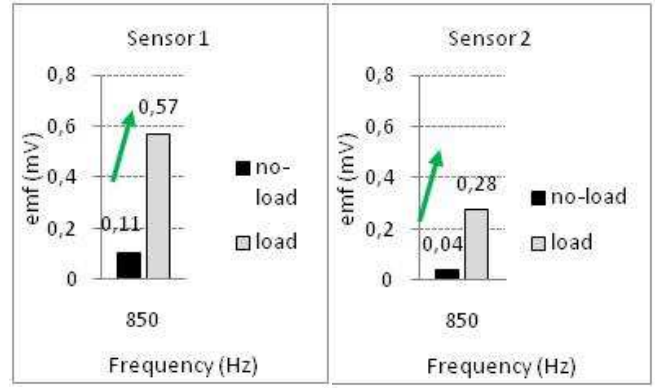

(a) Healthy machine

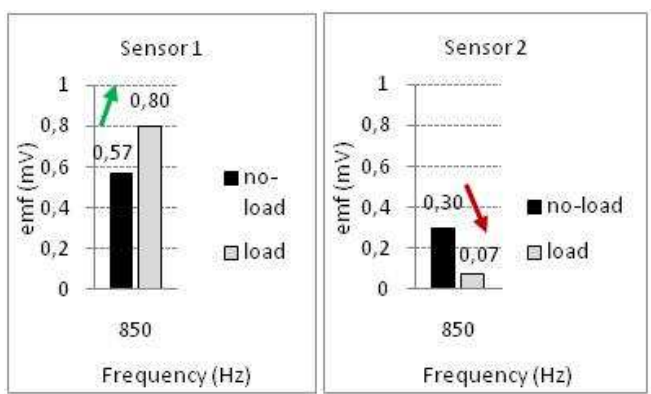

(b) Faulty machine

Fig. 2. Harmonic components at $850 \mathrm{~Hz}$ under both measurement positions for motor operation case

\section{Discussion}

The method presents several advantages:

- As far as the inter-turn short circuit fault is concerned, the external magnetic field is more sensitive than the current because the short circuit current generates its own magnetic effect.

- The main advantage is that the method is not based on the comparison with the healthy state as it exploits the magnitude variation of sensitive spectral lines with the load. Therefore, it does not require the knowledge of the healthy state.

- Furthermore, the method is not sensitive to supply voltage imbalance because it exploits the internal dissymmetry generated by the fault.

- The method can be applied to the synchronous and induction machine. The only condition is related to the presence of a rotor saliency because the sensitive spectral lines are tied to rotor permeance ranks. For induction machines and smooth rotor synchronous machines the saliency is due to rotor slots. For salient pole synchronous machines, the saliency corresponds to rotor poles. So, as the number of pole is $2 p$, the number of saliency per pole pair is always 2: $N^{r}=2$. Moreover, synchronous machines rotate at synchronous speed, therefore the slip $s$ is null. In the case of synchronous machines one must take $N^{r}=2, s=0$ in Eq. (2) and (3).

However, the method has also some limitations:

- As highlighted by analytical developments, the method cannot be applied to 2-pole machines as it is based on the difference between electrical and geometrical positions.

- It has been shown in [45] that the property about difference of variation is true only when the sensors are placed in the axis of the faulty winding. Therefore, to increase the reliability of the methods, measurements at several positions will be performed and analysis of spectral line variations will be done with belief functions.

\section{BELIEF FUNCTIONS: BASIC CONCEPTS}

Basic useful concepts of the belief function theory are exposed in this section. Belief functions offer a rich and flexible mathematical frame to represent and manipulate 
imperfect information.

\section{A. Representation of the available information}

Let us consider a variable of interest $\mathbf{x}$ taking its values in a finite set $\Omega=\left\{x_{1}, \ldots, x_{K}\right\}$ called the frame of discernment. A piece of information regarding the true value taken by $\mathbf{x}$ can be represented by a mass function (MF) $m$ defined as an application from the power set of $\Omega$ denoted by $2^{\Omega}=$ $\{A \mid A \subseteq \Omega\}=\left\{\varnothing,\left\{x_{1}\right\},\left\{x_{2}\right\},\left\{x_{1}, x_{2}\right\}, \ldots\right\}$ to $[0,1]$ such that:

$$
\sum_{A \subseteq \Omega} m(A)=1 .
$$

With $A$ a subset of $\Omega$, a mass $m(A)$ represents the degree of knowledge in favor of the fact that the true value of $\mathbf{x}$ belongs to $A$. The mass $m(\Omega)$ represents then the degree of total ignorance regarding the value taken by $\mathbf{x}$, especially $m(\Omega)=1$ represents a total uncertainty on the value taken by $\mathbf{x}$ (indicating $\mathbf{x} \in \Omega$ for sure does not bring any new piece of evidence concerning the searched value taken by $\mathbf{x}$ ).

\section{B. Combining evidence}

Two pieces of information represented respectively by MFs $m_{1}$ and $m_{2}$, and coming from two distinct sources, can be combined using the Conjunctive Rule of Combination (CRC) $[46,47]$ defined by:

$$
m_{1} \cap m_{2}(A)=\sum_{B \cap C=A} m_{1}(B) m_{2}(C), \quad \forall A \subseteq \Omega .
$$

This rule being associative and commutative, the order the sources are combined does not affect the combination result.

Let us consider as an example a very simple diagnosis problem with a frame $\Omega$ composed of two elements $y$ and $n$, $\Omega=\{y, n\}$, where "y" means "yes, there is a fault in the inspected winding" and " $n$ " means "no, there is no fault". Let us suppose two independent and reliable experts $E_{1}$ and $E_{2}$ expressing their opinions regarding the presence of a fault with, respectively, the two following MFs $m_{1}$ and $m_{2}$ defined, respectively, by $m_{1}(\{y\})=0.1, \quad m_{1}(\Omega)=0.9$, $m_{2}(\{y\})=0.2$ and $m_{2}(\Omega)=0.8$. Both experts think there is a small chance there is a fault but are not sure at all of the presence of a fault. A large mass $\left(90 \%\right.$ for expert $\mathrm{E}_{1}$ and $80 \%$ for expert $\mathrm{E}_{2}$ ) is on the ignorance regarding the fact that there is a fault.

The combination or fusion, denoted by $m$, of pieces of information $m_{1}$ and $m_{2}$ using CRC rule (7) is illustrated in Table 1 and given by $m(\{y\})=0.02+0.08+0.18=0.28$, and $m(\Omega)=0.72$. The mass supporting the fact that there is a fault has then been reinforced using the CRC rule.
TABLE 1

CONJUNCTIVE COMBINATION OF MASS FUNCTIONS $m_{1}$ AND $m_{2}$

\begin{tabular}{c|c|c}
\hline$m_{1}$ & $\{y\}$ & $\Omega$ \\
$\{y\}$ & 0.2 & 0.8 \\
0.1 & $\{y\} \cap\{y\}=\{y\}$ & $\{y\} \cap \Omega=\{y\}$ \\
$\Omega$ & $0.1 \times 0.2=0.02$ & $0.1 \times 0.8=0.08$ \\
\hline 0.9 & $\Omega \cap\{y\}=\{y\}$ & $\Omega \cap \Omega=\Omega$ \\
\hline \hline
\end{tabular}

\section{Decision Making}

A way to make a decision $[46,48]$ once the available information concerning the true value taken by $\mathbf{x}$ is represented by a single MF $m$, consists in transforming this MF $m$ into the following probability measure BetP defined by

$$
B e t P(\{x\})=\sum_{x \in A, A \subseteq \Omega} \frac{m(A)}{|A|(1-m(\varnothing))}, \forall x \in \Omega
$$

The chosen decision is the one maximizing BetP. As an example, BetP measure associated with MF $m$ depicted in Table 1 is given by:

$$
\begin{aligned}
\operatorname{BetP}(\{y\}) & =m(\{y\})+m(\{y, n\}) / 2 \\
& =0.28+0.72 / 2=0.64
\end{aligned}
$$

and

$$
\begin{aligned}
\operatorname{BetP}(\{n\}) & =m(\{n\})+m(\{y, n\}) / 2 \\
& =0+0.72 / 2=0.36
\end{aligned}
$$

The chosen decision is the one maximizing BetP, which is the one in favor of " $y$ " meaning "there is a fault".

\section{FAULT DETECTION WITH FUSION METHOD}

Fusion methods applied to electrical machines generally use variables like the currents, the vibration, or the temperature [40-42]. In this section, we expose how to use the measurements of two flux sensors obtained at different positions around the housing of an induction machine to indicate the presence of a fault. More precisely, we propose a fusion process taking into account, for each position of the sensors:

1. The difference of variation (DoV) of the measurements output by each sensor (cf fig. 2.) for the harmonic of interest (denoted by $\hat{b}_{K}^{* x}$ in Section II) while the load increases. This piece of information has already been exploited in [45].

2. An additional piece of information, which is the ratio of the amplitudes (RoA) output by the sensors for the harmonic of interest.

Information DoV and RoA can be obtained for different positions of the two sensors as illustrated in Fig 3. The number $N$ of possible positions, which can be used, depends on the size of the machine and the possibility to place sensors on the housing of the machine. For instance, in Fig 3, it is not possible to place a sensor under the machine on account of its plinth, and only four positions are possible. 
To model the fusion and how far each piece of information indicates a fault, we use the belief function framework presented in Section III.

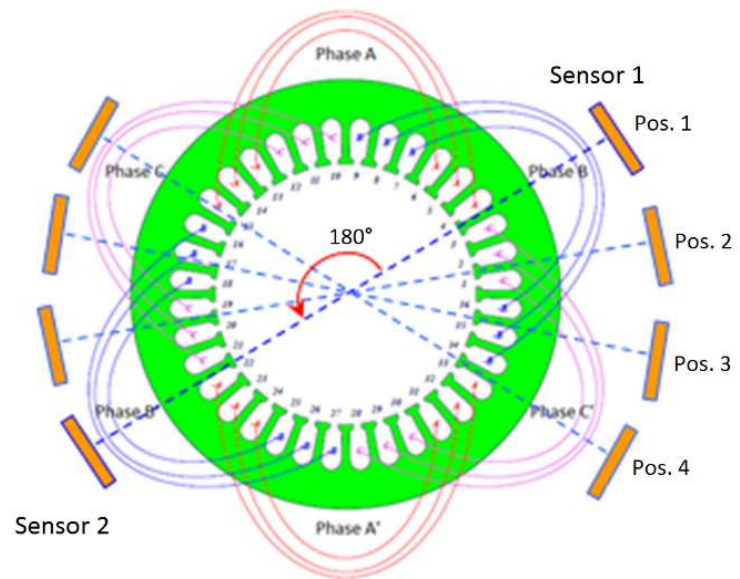

Fig. 3. Illustration of four possible positions for the sensors around the induction machine housing. The figure also gives the positions of the coils in the stator yoke for a synchronous machine adapted to create faults by short circuiting coils.

In the diagnosis problem tackled here, the variable of interest concerns the presence of a fault. The chosen frame of discernment $\Omega$ is then composed of two elements " $y$ " and " $n$ ", $\Omega=\{y, n\}$, such that

- " $y$ "stands for "yes, there is a fault in the winding of the machine";

- " $n$ "indicates"there is no fault".

For a given position $i$ of the sensors, it remains to build the pieces of information $m_{V, i}$ and $m_{A, i}$ regarding the presence of a fault, which comes respectively from the pieces of evidence DoV and RoA.

Mass function $m_{V, i}$ has been defined as follows:

- If there is at least one difference of evolution between sensors measurements while the load increases, then $m_{V, i}(\{y\})=0.95$ and $m_{V, i}(\Omega)=0.05$. It represents the fact that there is surely a fault.

- Otherwise (there is no opposite evolutions), we do not know if there is a fault, and there is a small chance that there is no fault, so we define $m_{V, i}$ by $m_{V, i}(\{n\})=0.05$ and $m_{V, i}(\Omega)=0.95$.

The second piece of evidence $m_{A, i}$ regarding the presence of a fault is defined using the following ratio $R_{i}$ between measurements $m e s_{1, i}$ and $m e s_{2, i}$ output respectively by sensor 1 and sensor 2 in position $i$ :

$$
R_{i}=\frac{\min \left(\text { mes }_{1, i}, \text { mes }_{2, i}\right)}{\max \left(\text { mes }_{1, i}, \text { mes }_{2, i}\right)}
$$

Values of ratio $R_{i}$ belong to $[0,1]$. When ratio $R_{i}$ is close to 1 , it means that the two measurements are close and then the machine is in a healthy state. When close to 0 , we are almost sure that there is a fault. Between 0 and 1, we suppose the existence of two thresholds $S_{1}$ and $S_{2}$ representing a transition. One example of the evolution of the mass function according to the ratio $R_{i}$ is given in Fig. 4 with $S_{1}=0.45$ and $S_{2}=0.55$. The area between $S_{1}$ and $S_{2}$ represents a transition area between the two views.

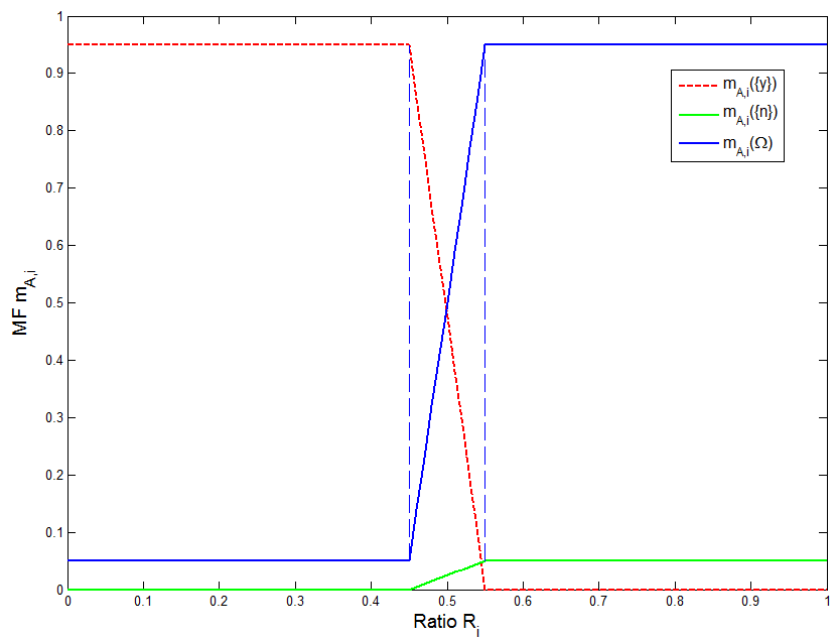

Fig. 4. Definition of mass function (MF) $m_{A, i}$ according to ratio $R_{i}$ value with $S_{1}=0.45$ and $S_{2}=0.55$.

With $N$ the number of possible positions, we then have $2 N$ mass functions $m_{V, i}$ and $m_{A, i}$ corresponding to $2 N$ pieces of information regarding the presence of a fault on the machine. These pieces of information are then combined using CRC (Eq. 7). The resulting mass function $m$ is given by

$$
m=\left(\bigcap_{i=1}^{N} m_{V, i}\right) \bigcap\left(\bigcap_{i=1}^{N} m_{A, i}\right)
$$

The chosen decision is then the one maximizing the probabilistic transformation BetP of $m$ (cf Eq. 8).

\section{EXPERIMENTATION}

This section presents an application of the diagnosis method detailed in Section IV.

\section{A. Description of the experimental test bench}

Coil sensors are designed in concordance with the machine dimension [45]. They are simple flux sensors with 200 turns built in our lab. They must be placed in opposite position around of the machine as shown in Fig. 5. The location of the flux sensors around the machine is greatly conditioned by the geometry of the machine frame and it influences the performances of the fault detection procedure. Ideally, the best position is to place the sensors just in front of the faulty phase, but practically it is not always possible to cover the whole periphery of the machine. Consequently to improve the diagnosis, data are analyzed from several positions.

Tests have been realized on two different machines. The first one is a squirrel-cage induction motor characterized by: 
$p=4,11 \mathrm{~kW}, 380 / 660 \mathrm{~V}, 50 \mathrm{~Hz}, 1450 \mathrm{tr} / \mathrm{min}, 32$ rotor bars $\left(N^{r}=16\right), 48$ stator slots $\left(N^{s}=24\right)$, and the second one is a salient-pole synchronous machine characterized by: $7.5 \mathrm{~kW}$, $p=2, N^{s}=18,50 \mathrm{~Hz}, 230 / 400 \mathrm{~V}$.

To make the tests, each machine has been rewound to allow a direct access of the terminals of the stator elementary sections. The induction machine designed to create multiple artificial inter-turn short-circuits is illustrated in Fig 6. This configuration allows one to make different degrees of fault severity in each of the 3 phases of the motor. Four sensor positions have been chosen as illustrated in Fig. 3.

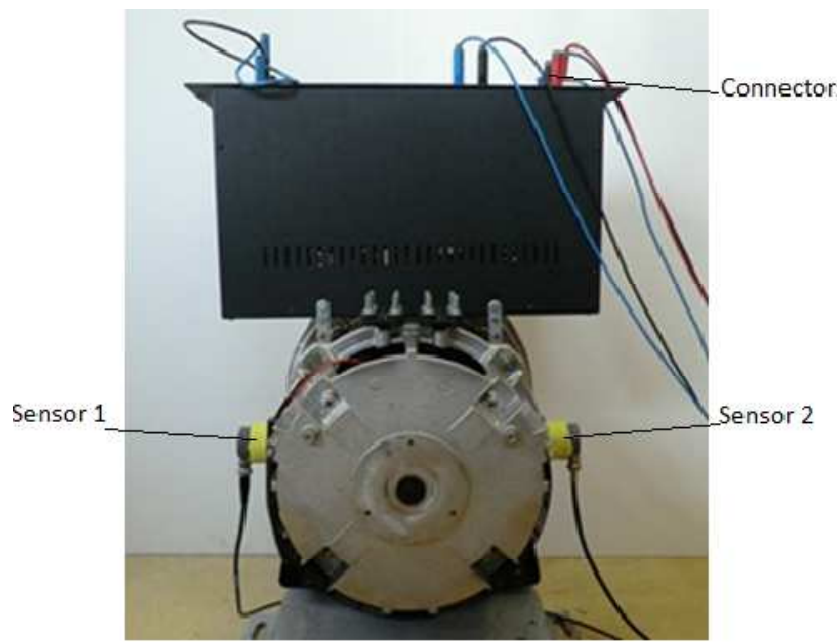

Fig. 5. One possible position for the pair of sensors, placed at $180^{\circ}$ from each other around the modified salient-pole synchronous machine adapted to create faults by short-circuiting coils.

Fig. 7 presents the electrical winding scheme of the induction machine as well as the connection possibilities between each winding section. In this figure, a short-circuit between section 1 and 2 is illustrated as an example. It corresponds to $12.5 \%$ of the whole windings of the phase A.

The salient-pole synchronous machine with sensors placed at $180^{\circ}$ from each other around the frame is shown in Fig. 5. The top and bottom positions are not accessible for measuring, so only three positions are considered in the left and right sides of the connector block fixed above the machine. The electrical winding scheme of the synchronous machine is presented in Fig. 8; it allows one to create artificial short circuit for inside coils $B_{i}$, middle coils $B_{m}$ and outside coils $B_{e}$ of the each motor phases. The minimal short circuit which can be realized when an elementary coil is short-circuited corresponds to $8.33 \%$ of the whole winding of one phase.

In order to analyze the external field evolution, tests are carried out in no load and load conditions. Four levels of load have been imposed for each machine. A rheostat limits the short circuit current to avoid total damage of the winding during the tests.

The harmonics of interest corresponding to the sensitive flux density components are $850 \mathrm{~Hz}$ for the induction machine and $150 \mathrm{~Hz}$ for the synchronous machine.

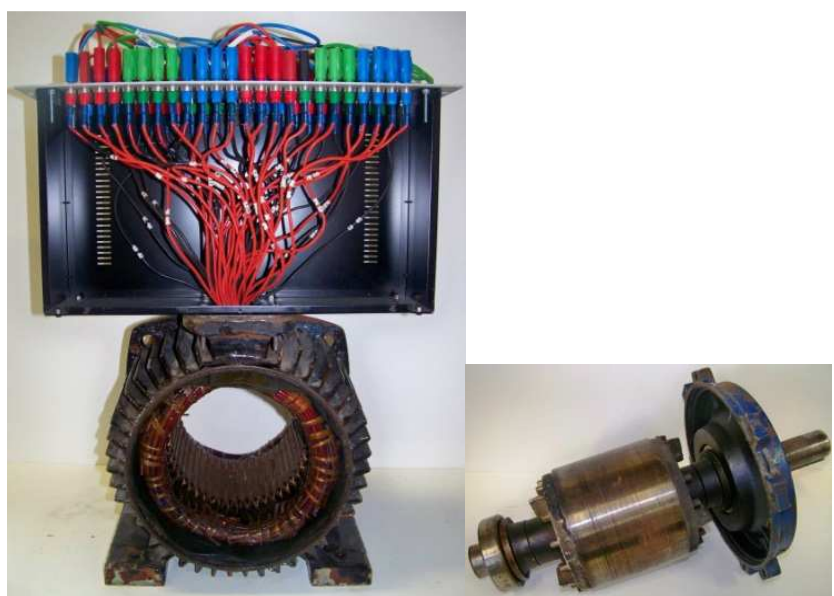

Fig. $6.11 \mathrm{~kW}$ induction machine modified to create faults by short circuiting coils. This machine allows one to make a minimal $12.5 \%$ of each phase coils in short-circuit.

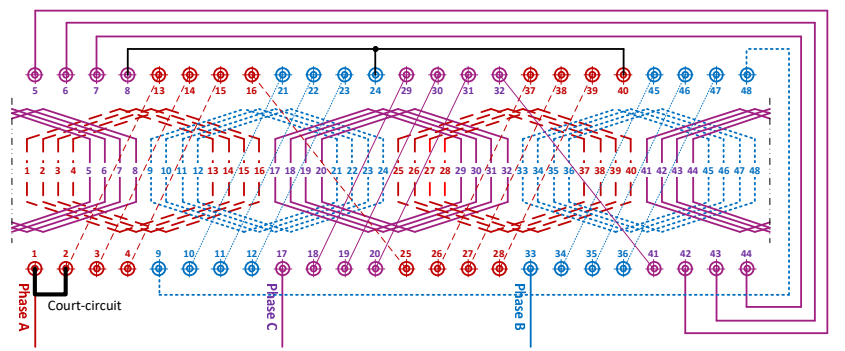

Fig. 7. Electrical winding schema of induction machine, which allows one to create faults in the phase A by short circuit realized in one elementary section (12.5\% of the coils).

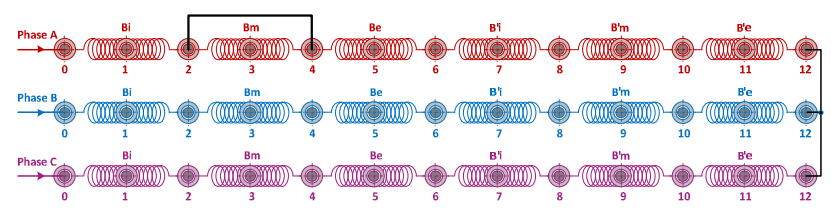

Fig. 8. Electrical winding schema of salient-pole synchronous machine which allows to create winding faults. Here the short circuit is represent for middle coil $B_{m}$ corresponding to $16.6 \%$ of the whole winding of the phase A.

\section{B. Calculation example}

We present here a calculation example for the proposed approach. In this example, four possible positions are considered and the measurements obtained by sensors are summarized in Table 2. In this situation, the machine has a short-circuit fault.

TABLE 2

850HZ HARMONIC MAGNITUDE OBTAINED FROM SENSORS 1 AND 2 USING THE INDUCTION MACHINE (FOUR POSITIONS).

\begin{tabular}{c|cc|cc|cc|cc}
\hline \hline $\begin{array}{c}\text { Load } \\
(\mathrm{W})\end{array}$ & \multicolumn{2}{|c|}{ Position 1 } & \multicolumn{2}{|c|}{ Position 2 } & Position 3 & \multicolumn{2}{c}{ Position 4} \\
\cline { 2 - 9 } & Sensor & Sensor & Sensor & Sensor & Sensor & Sensor & Sensor & Sensor \\
& $1(\mu \mathrm{V})$ & $2(\mu \mathrm{V})$ & $1(\mu \mathrm{V})$ & $2(\mu \mathrm{V})$ & $1(\mu \mathrm{V})$ & $2(\mu \mathrm{V})$ & $1(\mu \mathrm{V})$ & $2(\mu \mathrm{V})$ \\
\hline 0 & 46 & 126 & 98 & 206 & 101 & 122 & 84 & 146 \\
\hline 600 & 24 & 235 & 160 & 337 & 175 & 192 & 147 & 217 \\
\hline 1000 & 34 & 316 & 232 & 514 & 276 & 303 & 176 & 267 \\
\hline 1400 & 163 & 387 & 368 & 625 & 389 & 401 & 248 & 356 \\
\hline \hline
\end{tabular}

Differences of variations for each sensor at Position 1 are exposed in Table 3 
TABLE 3

DIFFERENCES OF VARIATIONS OBTAINED FROM SENSORS 1 AND 2 USING THE INDUCTION MACHINE FOR POSITION 1.

\begin{tabular}{c|c|c|c|c|c}
\hline \hline $\begin{array}{c}\text { Load } \\
(\mathrm{W})\end{array}$ & $\begin{array}{c}\text { Sensor 1 } \\
(\mu \mathrm{V})\end{array}$ & $\begin{array}{c}\text { Sensor 1 } \\
\text { Variation }\end{array}$ & $\begin{array}{c}\text { Sensor 2 } \\
(\mu \mathrm{V})\end{array}$ & $\begin{array}{c}\text { Sensor 2 } \\
\text { Variation }\end{array}$ & $\begin{array}{c}\text { Same } \\
\text { direction? }\end{array}$ \\
\hline 0 & 46 & & 126 & & \\
\hline 600 & 24 & $\mathbf{2 2}$ & 235 & $\mathbf{- 1 0 9}$ & no \\
\hline 1000 & 34 & -10 & 316 & -81 & yes \\
\hline 1400 & 163 & -129 & 387 & -71 & yes \\
\hline \hline
\end{tabular}

It can be observed from Table 3 that in Position 1, when the load increases from 0 to $600 \mathrm{~W}$ Sensor 1 measurement decreases from $46 \mu \mathrm{V}$ to $24 \mu \mathrm{V}$ while Sensor 2 measurement increases from $126 \mu \mathrm{V}$ to $235 \mu \mathrm{V}$. Variations in opposite direction are obtained.

Table 4 summarizes the number of different variations observed for all positions.

TABLE4

NUMBER OF DIFFERENT VARIATIONS DETECTED FOR EACH POSITION OF THE SENSORS.

\begin{tabular}{c|c|c|c|c}
\cline { 2 - 5 } & Position 1 & Position 2 & Position 3 & Position 4 \\
\hline $\begin{array}{c}\text { Nb of } \\
\text { different } \\
\text { variation }\end{array}$ & 1 & 0 & 0 & 0 \\
\hline \hline
\end{tabular}

Consequently the obtained mass functions $m_{V, i}$, for each position $i, i=1, \ldots, 4$ are given in Table 5 .

TABLE 5

MFs, $m_{V, i}$ OBTAINED FROM THE MEASUREMENTS EXPOSED IN TABLE 2.

\begin{tabular}{c|c|c|c}
\hline \hline Position 1 & Position 2 & Position 3 & Position 4 \\
\hline$m_{V, 1}(\{y\})=0.95$ & $m_{V, 2}(\{n\})=0.05$ & $m_{V, 3}(\{n\})=0.05$ & $m_{V, 4}(\{n\})=0.05$ \\
$m_{V, 1}(\Omega)=0.05$ & $m_{V, 2}(\Omega)=0.95$ & $m_{V, 3}(\Omega)=0.95$ & $m_{V, 4}(\Omega)=0.95$ \\
& & & \\
\hline \hline
\end{tabular}

As a difference of evolution was detected in Position 1, MF $m_{V, 1}$ indicates the presence of a fault, whereas it is not the case for positions 2, 3 and 4 .

Result after the combination (Eq. 7) of these $4 \mathrm{MFs}$ is given by:

$$
m_{V}(\{y\})=0.814, m_{V}(\{n\})=0.007, m_{V}(\Omega)=0.043, m_{V}(\varnothing)=0.136
$$

We consider now the ratio of the amplitudes (RoA) as a second piece of information regarding the presence of a fault. Ratios obtained in Position 1 are presented in Table 6. Only the smallest is conserved for $R_{1}$.

Ratios $R_{2}, R_{3}$ and $R_{4}$ are similarly computed for positions 2, 3 and 4. Associated MFs are then computed (cf Section IV, Fig. 4). Results are summarized in Table 7.
TABLE 6

RATIOS OBTAINED FROM THE MEASUREMENTS OF TABLE 2 IN POSITION 1.

\begin{tabular}{c|c|c|c|c}
\hline \hline $\begin{array}{c}\text { Load } \\
(\mathrm{W})\end{array}$ & $\begin{array}{c}\text { Sensor 1 } \\
(\mu \mathrm{V})\end{array}$ & $\begin{array}{c}\text { Sensor 2 } \\
(\mu \mathrm{V})\end{array}$ & Ratio & \multirow{2}{*}{$R_{1}$} \\
\hline 0 & 46 & 126 & 0.365 & \multirow{2}{*}{$\mathbf{0 . 1 0 2}$} \\
\hline 600 & 24 & 235 & $\mathbf{0 . 1 0 2}$ & \\
\hline 1000 & 34 & 316 & 0.107 & \\
\hline 1400 & 163 & 387 & 0.421 & \\
\hline \hline
\end{tabular}

TABLE 7

MFS, $m_{A, i}$, OBTAINED WITH THE EXAMPLE MEASUREMENT OF TABLE 2.

\begin{tabular}{c|c|c|c}
\hline \hline $\begin{array}{c}\text { Position 1 } \\
\left(R_{1}=0.102\right)\end{array}$ & $\begin{array}{c}\text { Position 2 } \\
\left(R_{2}=0.475\right)\end{array}$ & $\begin{array}{c}\text { Position 3 } \\
\left(R_{3}=0.828\right)\end{array}$ & $\begin{array}{c}\text { Position 4 } \\
\left(R_{4}=0.575\right)\end{array}$ \\
\hline$m_{A, 1}(\{y\})=0.95$ & $m_{A, 2}(\{y\})=0.71$ & $m_{A, 3}(\{y\})=0$ & $m_{A, 4}(\{y\})=0$ \\
$m_{A, 1}(\{n\})=0$ & $m_{A, 2}(\{n\})=0.02$ & $m_{A, 3}(\{n\})=0.05$ & $m_{A, 4}(\{n\})=0.05$ \\
$m_{A, 1}(\Omega)=0.05$ & $m_{A, 2}(\Omega)=0.27$ & $m_{A, 3}(\Omega)=0.95$ & $m_{A, 4}(\Omega)=0.95$ \\
\hline \hline
\end{tabular}

The combination of these MFs yields to:

$m_{V}(\{y\})=0.872, m_{V}(\{n\})=0.003, m_{V}(\Omega)=0.012, m_{V}(\varnothing)=0.113$

Combining $m_{A}$ and $m_{V}$ gives a MF defined by:

$m_{V}(\{y\})=0.757, m_{V}(\{n\})=0.001, m_{V}(\Omega)=0.001, m_{V}(\varnothing)=0.241$

At last, the transformation of $m$ into a probability (Eq. 8) is given by

$$
\operatorname{Bet} P(\{y\})=0.999, \operatorname{Bet} P(\{n\})=0.001
$$

It follows a decision in favor of $\{y\}$.

\section{Results}

To test more deeply the method exposed in Section IV, two test benches with different machines are considered: one with the induction machine and another one with the synchronous machine presented earlier.

For the first one using the induction machine, four series (called series 1, 2, 3 and 4) of measurements have been taken. One series is relative to one healthy case, plus 12 faulty cases corresponding to faults at different positions. One case takes into account several load level, and signals picked up by two sensors placed at four positions as depicted in section V.B. The four series are similar; the aim is to increase the number of cases and to check the repetitiveness and the robustness of the method. The results for this machine are presented in Table 8. In this table, the results are given as percentage of correct detections. Three methods are studied: the first one uses only information regarding the difference of variation (DoV), the second one using only information regarding the amplitude ratio (RoA) and the last one using both. For each series, the best result is obtained by combining all the information as it can be seen in the last row of Table 8 . Overall, we see that the results obtained using all the information allow us to achieve the best results $(98.1 \%$ against $94.2 \%$ with information regarding only the amplitude ratio and $86.5 \%$ with information regarding only the difference of variation). 
TABLE 8

PERCENT OF CORRECT DECISIONS FOR EACH SERIES WITH INDUCTION MACHINE. THE NUMBER IN BRACKETS INDICATES THE NUMBER OF NO DETECTION. THE BEST RESULT IS HIGHLIGHTED IN BOLD FONT.

\begin{tabular}{|c|c|c|c|c|c|}
\hline & $\begin{array}{c}\text { Results } \\
\text { of } \\
\text { Series } \\
1\end{array}$ & $\begin{array}{c}\text { Results } \\
\text { of } \\
\text { Series } \\
2\end{array}$ & $\begin{array}{c}\text { Results } \\
\text { of } \\
\text { Series } \\
3\end{array}$ & $\begin{array}{c}\text { Results } \\
\text { of } \\
\text { Series } \\
4\end{array}$ & $\begin{array}{l}\text { Overall } \\
\text { Results }\end{array}$ \\
\hline $\begin{array}{l}\text { Fusion of only information } \\
\text { regarding the difference of } \\
\text { variation in each position } \\
\left(\cap_{i=1}^{\cap} m_{V, i}\right)\end{array}$ & $\begin{array}{c}92.3 \\
(1)\end{array}$ & $\begin{array}{c}84.6 \\
(2)\end{array}$ & $\begin{array}{c}76.9 \\
(3)\end{array}$ & $\begin{array}{c}92.3 \\
(1)\end{array}$ & $\begin{array}{c}86.5 \\
(7)\end{array}$ \\
\hline $\begin{array}{l}\text { Fusion of only information } \\
\text { regarding the amplitude ratio } \\
\text { in each position }\left(\cap_{i=1}^{\cap} m_{A, i}\right)\end{array}$ & $\begin{array}{c}100 \\
(0)\end{array}$ & $\begin{array}{c}92.3 \\
(1)\end{array}$ & $\begin{array}{c}92.3 \\
(1)\end{array}$ & $\begin{array}{c}92.3 \\
(1)\end{array}$ & $\begin{array}{c}94.2 \\
(3)\end{array}$ \\
\hline $\begin{array}{l}\text { Fusion of all the mass } \\
\text { functions } \\
\left.\underset{i=1}{4}{ }_{i=1}^{\cap} m_{V, i}\right) \cap( \\
\left.\mathrm{C}_{A, i}\right)\end{array}$ & $\begin{array}{r}100 \\
(0)\end{array}$ & $\begin{array}{c}92.3 \\
(1)\end{array}$ & $\begin{array}{c}100 \\
(0)\end{array}$ & $\begin{array}{c}100 \\
(0)\end{array}$ & $\begin{array}{c}98.1 \\
(1)\end{array}$ \\
\hline
\end{tabular}

For the second test using the synchronous machine, three series have been realized (called series 1, 2 and 3). Here, one series corresponds to one healthy case plus 18 faulty cases. One case consider several loads and signals picked up by two sensors placed at only three positions because there is not enough place around the machine to take more measurements. Results are presented in Table 9. In the same manner as the first test using the induction machine, we note that using both pieces of information for all positions leads to the best result (89.5\% against $73.7 \%$ with information regarding only the amplitude ratio and $57.9 \%$ with information regarding only the difference of variation).

Comparing the best results obtained for induction machine and synchronous machine (Table 8 and Table 9) it can be noticed that there is roughly a $10 \%$ difference between the overall results. This is consequence of more important number of measurement positions considered in conjunctive combination for induction machine $(\mathrm{N}=4$ for induction machine and $\mathrm{N}=3$ for synchronous machine). This difference brings the light on the fact that using belief functions can improve the fault detection even for different machines and different measurement positions.

The results of the proposed approach were obtained by setting the values of $S_{1}$ and $S_{2}$ to 0.45 and 0.55 respectively. To study the impact of these parameters, we vary the value of $S_{1}$ in $[0,0.9]$ and we set the value of $S_{2}$ at $S_{1}+0.1$. Fig 9 and Fig. 10 show the percent of correct decisions according to $S_{1}$ for each piece of information and each machine (induction and synchronous). The results obtained only with the DoV information, are independent of parameters $S_{1}$ and $S_{2}$. For $S_{1}$ $=0.45$, we find results presented in Table 8 and Table 9 . These tests highlight that whatever the values of these parameters, the performance of the fusion approach is always at least as good as approaches based only on the difference of variation (DoV) or amplitude ratio (RoA) as shown in figures Fig. 9 and
Fig 10.

For a new diagnosis, we then recommend to set the values of $S_{1}$ and $S_{2}$ to 0.45 and 0.55 respectively, the method introduced having then not to know the healthy state of the machine and no thresholds have to be compulsory determined before using this diagnosis process.

TABLE 9

PERCENT OF CORRECT DECISIONS FOR EACH SERIES WITH SYNCHRONOUS MACHINE. THE NUMBER IN BRACKETS INDICATES THE NUMBER OF NO DETECTION. THE BEST RESULT IS HIGHLIGHTED IN BOLD FONT.

\begin{tabular}{|c|c|c|c|}
\hline $\begin{array}{l}\text { Results } \\
\text { of } \\
\text { Series 1 }\end{array}$ & $\begin{array}{l}\text { Results } \\
\text { of } \\
\text { Series } 2\end{array}$ & $\begin{array}{l}\text { Results } \\
\text { of } \\
\text { Series } 3\end{array}$ & $\begin{array}{l}\text { Overall } \\
\text { Results }\end{array}$ \\
\hline $\begin{array}{c}57.9 \\
(8)\end{array}$ & $\begin{array}{l}47.4 \\
(10)\end{array}$ & $\begin{array}{c}68.4 \\
(6)\end{array}$ & $\begin{array}{l}57.9 \\
(24)\end{array}$ \\
\hline $\begin{array}{c}78.9 \\
(4)\end{array}$ & $\begin{array}{c}68.4 \\
(6)\end{array}$ & $\begin{array}{c}73.7 \\
(5)\end{array}$ & $\begin{array}{l}73.7 \\
(15)\end{array}$ \\
\hline $\begin{array}{c}100 \\
(0)\end{array}$ & $\begin{array}{c}84.2 \\
(3)\end{array}$ & $\begin{array}{c}84.2 \\
(3)\end{array}$ & $\begin{array}{c}89.5 \\
(6)\end{array}$ \\
\hline
\end{tabular}

\begin{tabular}{|c|c|c|c|c|}
\hline$\left.\bigcap_{i=1}^{3} m_{V, i}\right) \cap(\overbrace{i=1}^{3} m_{A, i})$ & $\begin{array}{c}100 \\
(\mathbf{0})\end{array}$ & $\begin{array}{c}84.2 \\
\text { (3) }\end{array}$ & $\begin{array}{c}84.2 \\
(3)\end{array}$ & $\begin{array}{c}89.5 \\
(6)\end{array}$ \\
\hline
\end{tabular}

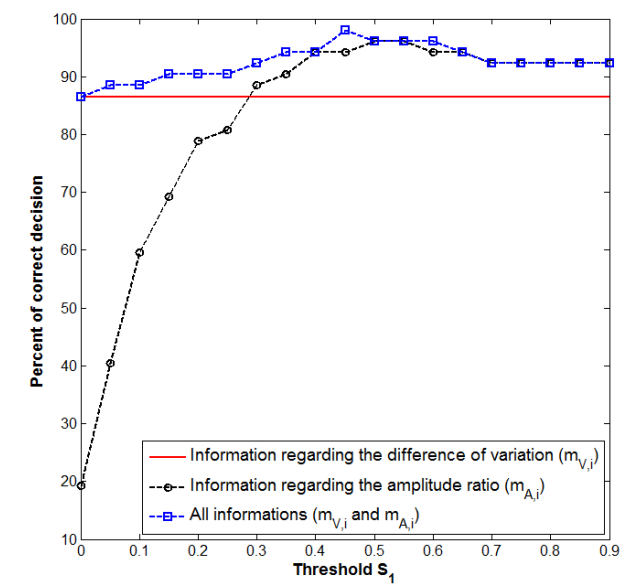

Fig. 9: Percent of correct decisions according to threshold $S_{1}$ for the induction machine.

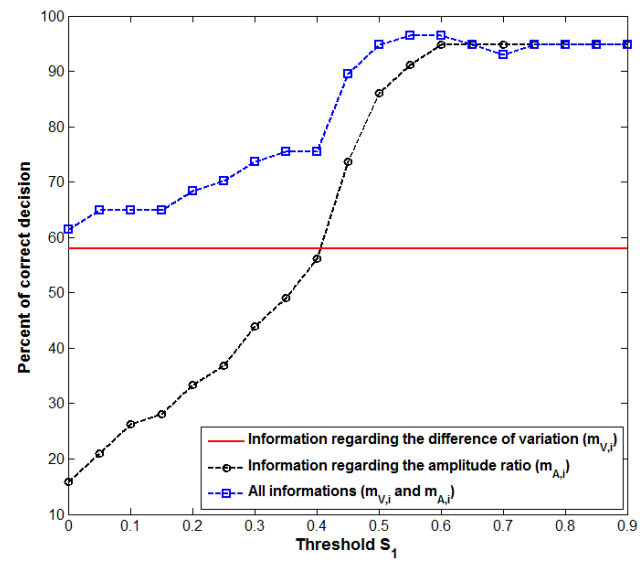

Fig. 10: Percent of correct decisions according to threshold $S_{1}$ for the synchronous machine. 


\section{CONCLUSION}

The method proposed in the paper uses external magnetic field measured in the vicinity of rotating electrical machines associated with a fusion process based on belief function theory which increases the performance in detection of incipient short-circuit faults.

Compared with other existing methods, our method does not need a learning stage for fault detection. Therefore the detection procedure does not need the knowledge of the healthy state and it is not based on a comparison between the current state with a previous healthy state of the machine. Moreover, the method does not need the knowledge of the model of the machine and does not require advanced signal processing techniques. Only the frequency of a sensitive spectral line in the external magnetic field is needed.

The original contribution is the application of fusion technique to external magnetic field of electrical machine for fault detection while fusion approaches to electrical machines generally exploits other physical variables (vibrations, currents, temperature). The method gives good results on salient pole synchronous machines or on induction machines. For example, taking into consideration the frame of a real machine, when the sensors cannot be positioned in the best position, only few signals measured in accessible positions are used for detection, namely: the variation (DoV) of the sensitive harmonics measured by each sensor and the ratio of their amplitudes (RoA). Taken separately, DoV or RoA can give a detection probability around $70 \%$, but combined with the proposed fusion process, the detection probability increases to about $90 \%$, which therefore illustrates the interest of these present works using information fusion techniques

The method has also the advantage of requiring simple and cheap wound flux sensors, it does not need online signal processing; the signal delivered by each sensor can be only recorded and the data can be treated afterwards. The used algorithms are FFT, and a fusion algorithm which does not require high computation time.

\section{REFERENCES}

1] P. Tavner, L. Ran, J. Penman, and H. Sedding, Condition Monitoring of Rotating Electrical Machines, 2 ed. London, United Kingdom: Institution of Engineering and Technology, 2008

[2] M. Riera-Guasp, J. A. Antonino-Daviu and G. A. Capolino, "Advances in Electrical Machine, Power Electronic, and Drive Condition Monitoring and Fault Detection: State of the Art", IEEE Trans. Ind. Electron., vol. 62, n³, pp. 1746-1759, March 2015.

[3] B. Xiao, S. Yin, O. Kaynak, "Tracking Control of Robotic Manipulators With Uncertain Kinematics and Dynamics", IEEE Transactions on Industrial Electronics, vol. 63, n¹0, pp. 6439-6449, Oct. 2016.

[4] B. Xiao, S. Yin, "Velocity-Free Fault-Tolerant and Uncertainty Attenuation Control for a Class of Nonlinear Systems", IEEE Transactions on Industrial Electronics, vol. 63, n 7 , pp. 4400-4411, July 2016.

[5] P. Zhang, Y. Du, T. G. Habetler, and B. Lu, "A survey of condition monitoring and protection methods for medium-voltage induction motors," IEEE Trans. Ind. Appl., vol. 47, $\mathrm{n}^{\circ} 1$, pp. 34-46, Jan./Feb. 2011.

[6] IEEE, "Report of Large Motor Reliability Survey of Industrial and Commercial Installations, Part I," IEEE Trans. Ind. Appl., vol. IA-21, pp. 853-864, 1985.
[7] W. T. Thomson and M. Fenger, "Current signature analysis to detect induction motor faults," IEEE Ind. Appl. Mag., vol. 7, n4, pp. 26-34, Jul./Aug. 2001.

[8] A. Stavrou, H.G. Seddings and J. Penman, "Current monitoring for detecting inter-turn short circuits in induction motors", IEEE Trans. on Energy Conversion, vol. 16, n ${ }^{\circ}$, pp. 32-37, March 2001.

[9] G. A. Capolino, J. A. Antonino-Daviu and M. Riera-Guasp, "Modern Diagnostics Techniques for Electrical Machines, Power Electronics, and Drives", IEEE Trans. Ind. Electron., vol. 62, n³, pp. 1738-1745, March 2015.

[10] A.S. Bano, M. Pineda-Sanchez, R. Puche-Panadero, J. Martinez-Roman; D. Matic, "Fault Diagnosis of Rotating Electrical Machines in Transient Regime Using a Single Stator Current's FFT", IEEE Transactions on Instrumentation and Measurement, vol. 64, n¹1, pp. 3137-3146, June 2015.

[11] A. Khezzar, M. Y. Kaikaa, M. El Kamel Oumaamar, M. Boucherma and H. Razik, " On the use of slot harmonics as a potential indicator of rotor bar breakage in the induction machine", IEEE Trans. Ind. Electron., vol. 56, n¹1, pp. 4592-4605, Nov. 2009.

[12] G.R. Bossio, C.H. De Angelo, J. M. Bossio, C.M. Pezzani and G. O. Garcia "Separating broken rotor bars and load oscillations on IM Fault Diagnosis Through the Instantaneous Active and Reactive Currents", IEEE Trans. Ind. Electron., vol. 56, n ${ }^{\circ} 1$, pp. 4571 - 4580, Nov. 2009.

[13] T. Ghanbari, A. Farjah, "A Magnetic Leakage Flux-Based Approach for Fault Diagnosis in Electrical Machines”, IEEE Sensors Journal, vol. 14, $\mathrm{n}^{\circ} 9$, pp. 2981 - 2988, April 2014.

[14] KT. Kim, ST. Lee; J. Hur, "Diagnosis Technique Using a Detection Coil in BLDC Motors With Interturn Faults", IEEE Transactions on Magnetics, vol. 50, $\mathrm{n}^{\circ} 2$, pp. 885-888, Feb. 2014.

[15] M. Biet, "Rotor Faults Diagnosis Using Feature Selection and Nearest Neighbors Rule: Application to a Turbogenerator", IEEE Transactions on Industrial Electronics, vol. 60, n⿳9 9, pp. 4063-4073, Sept. 2013.

[16] L. Frosini, A. Borin, L. Girometta, G. Venchi, "A novel approach to detect short circuits in low voltage induction motor by stray flux measurement", 20th International Conference on Electrical Machines (ICEM '12), pp. 1536 - 1542, Sept. 2012.

[17] H. Henao, C. Demian, and G.A. Capolino, "A frequency-domain detection of stator winding faults in induction machines using an external flux sensor", IEEE Trans. Ind. Appl., vol. 39, pp. 1272-1279, Sept/Oct. 2003.

[19] H. Henao, G.-A. Capolino, M. Fernandez-Cabanas, F. Filippetti, C. Bruzzese, E.Strangas, R. Pusca, J. Estima, M. Riera-Guasp, S. HedayatiKia, "Trends in Fault Diagnosis for Electrical Machines: A Review of Diagnostic Techniques", IEEE Ind. Electron. Mag., vol. 8, n², pp. 3142, June 2014.

[20] A. Ceban, R. Pusca, and R. Romary, "Study of rotor faults in induction motors using external magnetic field analysis", IEEE Trans. Ind. Electron., vol. 59, pp. 2082-2093, May 2012.

[21] L. Frosini, C. Harlisca, L. Szabo, "Induction Machine Bearing Fault Detection by Means of Statistical Processing of the Stray Flux Measurement”, IEEE Trans. Ind. Electron., vol. 62, n³, pp. 1846-1854, March 2015.

[22] H. Henao et al, "Trends in Fault Diagnosis for Electrical Machines: A Review of Diagnostic Techniques", IEEE Industrial Electronics Magazine, vol. 18, $\mathrm{n}^{\circ} 2$, pp. 31-42, June 2104.

[23] R. Romary, R. Corton, D. Thailly, and J. F. Brudny, "Induction machine fault diagnosis using an external radial flux sensor", The European Physical Journal - Applied Physics, vol. 32, pp. 125-132, 2005.

[24] R. Pusca, R. Romary, A. Ceban, and J.-F. Brudny, "An Online Universal Diagnosis Procedure Using Two External Flux Sensors Applied to the AC Electrical Rotating Machines", Sensors, vol. 10, pp. 10448-10466, November 2010.

[25] S. Bachir, S. Tnani, JC Trigeassou, G. Champenois, "Diagnosis by parameter estimation of stator and rotor faults occurring in induction machines”, IEEE Trans. Ind. Electron., vol. 53, n³, pp. 963-973 June 2006

[26] S. Toma, L. Capocchi, G.A. Capolino, "Wound-Rotor Induction Generator Inter-Turn Short-Circuits Diagnosis Using a New Digital Neural Network", IEEE Trans. Ind. Electron., vol. 60, n 9 , pp. 40434052, September 2013.

[27] M. Barzegaran, A. Mazloomzadeh, O.A. Mohammed, "Fault diagnosis of the asynchronous machines through magnetic signature analysis using 
finite-element method and neural networks", IEEE Trans. on Energy Conversion, vol. 28, pp. 1064-1071, October 2013.

[28] V. Delgado-Gomes, V. F. Pires, J. F. Martins, "A new teaching tool for fault detection in the induction machine", IEEE International Symposium on Industrial Electronics (ISIE), 23rd, pp. 2190 - 2195, June 2014.

[29] N. Lashkari, H.F Azgomi, J. Poshtan, M. Poshtan, "Robust stator fault detection under load variation in induction Motors using AI techniques" IEEE International Electric Machines \& Drives Conference (IEMDC), 10-13 May 2015, Istanbul, pp.1446 - 1451.

[30] L. Frosini, S. Zanazzo, A. Albini, "A Wavelet-based Technique to Detect Stator Faults in Inverter-fed Induction Motors", International Conference on Electrical Machines (ICEM), vol.22, 4-7 september2016, Lausanne, pp. 2919-2925.

[31] R. Kechida, A. Menacer, H. Talhaoui and H. Cherif, "Discrete wavelet transform for stator fault detection in induction motors," Diagnostics for Electrical Machines, Power Electronics and Drives (SDEMPED), 2015 IEEE 10th International Symposium on. Guarda, 2015, pp. 104-109.

[32] A. Berzoy, A. A. S. Mohamed, O. A.Mohammed, "Stator Winding Interturn Fault in InductionMachines: Complex-Vector Transient and SteadyState Modelling",International Conference on Electrical Machines (ICEM), vol.22, 4-7 September 2016, Lausanne, pp. 2901-2907.

[33] Y. Yagami, C. Araki, Y. Mizuno, H. Nakamura, "Turn-to-turn insulation failure diagnosis of stator winding of low voltage induction motor with the aid of support vector machine", IEEE Transactions on Dielectrics and Electrical Insulation, vol. 22, n 6, pp. 3099-3106, Jan. 2016.

[34] A. Soualhi, G. Clerc and H. Razik, "Detection and Diagnosis of Faults in Induction Motor Using an Improved Artificial Ant Clustering Technique", IEEE Transactions on Industrial Electronics, vol. 60, n9, pp. 4053-4062, Sept. 2013.

[35] O. Ondel, E. Boutleux, E. Blanco, G. Clerc, "Coupling Pattern Recognition With State Estimation Using Kalman Filter for Faul Diagnosis”, IEEE Trans. Ind. Electron., vol. 59, n¹1, pp. 4293-4300, November 2012.

[36] S. Yin, Member, X. Li, IEEE, H. Gao, O. Kaynak, "Data-Based Techniques Focused on Modern Industry: An Overview", IEEE Trans. Ind. Electron., vol. 62, n ${ }^{\circ}$, pp. 657-667, Jan. 2015.

[37] S. Yin, S.X. Ding, X. Xie, H. Luo, "A Review on Basic Data-Driven Approaches for Industrial Process Monitoring”, IEEE Trans. Ind. Electron., vol. 61, $\mathrm{n}^{\circ} 11$, pp. 6418-6428, Nov. 2014

[38] Yong-Wei Li, Wei Li, Xing-De Han, Jing Li, "Application of multisensor information fusion technology in the power transformer fault diagnosis", International Conference on Machine Learning and Cybernetics, vol. 1, pp. 29-33, pp. 12-15, July 2009.

[39] J. Hang, J. Zhang, M. Cheng, "Fault diagnosis of wind turbine based on multisensors information fusion technology", IET Renewable Power Generation, vol. 8, n³, pp. 289-298, March 2014.

[39] Z. Chen, W. Li, "Multisensor Feature Fusion for Bearing Fault Diagnosis Using Sparse Autoencoder and Deep Belief Network", IEEE Transactions on Instrumentation and Measurement, vol. 66, $\mathrm{n}^{\circ} 7$, pp. 1693-1702, March 2017.

[41] Feng Lu, Hai-Lian Du, Zhe-Jun Diao, Xi-Yuan Ju, "Rotor fault diagnosis based on fusion estimation of multi-circuit model of induction motor", Proceedings of 2004 International Conference on Machine Learning and Cybernetics, vol. 4, pp. 2157-2161, 26-29 August 2004.

[42] H. Jafari, J. Poshtan, "Fault isolation and diagnosis of induction motor based on multi-sensor data fusion", The 6th Power Electronics, Drive Systems \& Technologies Conference, PEDSTC2015, pp. 269-274, 3-4 Feb. 2015, Teheran.

[43] G. Shafer, A mathematical theory of evidence, Princeton University Press, Princeton, N.J., 1976.

[44] R. Romary, D. Roger, J.F. Brudny, "Analytical computation of an AC machine external magnetic field". European Physical Journal-Applied Physics EPJ-AP, EDP Sciences, Paris, vol. 47, n³, Paper 31101, Sept. 2009.

[45] R. Pusca, C. Demian, D. Mercier, E. Lefevre, R. Romary "Improvement of a diagnosis procedure for AC machines using two external flux sensors based on a fusion process with belief functions", 38th Annual conference on IEEE Industrial Electronics Society, IECON2012, 25-28 October 2012, Montreal, Canada, pp. 5078-5083.

[46] P. Smets and R. Kennes, "The Transferable Belief Model", Artificial Intelligence, vol. 66, pp. 191-243, 1994.

[47] P. Smets. "Analyzing the combination of conflicting belief functions", Information Fusion, vol. 8, n 4 , pp.387-412, 2007.
[48] T. Denœux, "Analysis of evidence-theoretic decision rules for pattern classification”, Pattern Recognition, vol. 30, pp. 1095-1107, 1997.

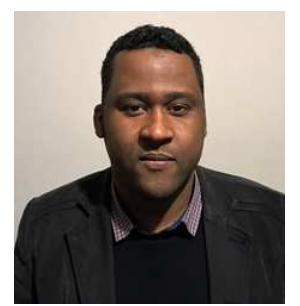

Miftah Irhoumah received the Master degree of Technology in Industrial Automation from the Faculty of Engineering in the University of Tripoli (Lybia) in 2008. He has technical experience in the electricity laboratories and automatic control. He is actually pursuing $\mathrm{PhD}$ studies in the Laboratory of Electrotechnical and Environmental Systems (LSEE), at Artois University in France in the field of diagnosis of electrical machines.

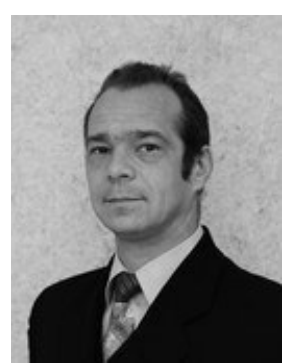

Remus Pusca was born in Medias, Romania, in 1972. He received in 1995 the electrical engineering degree from Technical University of Cluj-Napoca, Romania. He obtained in 2002 Ph.D. degree in electrical engineering, from the University of Franche-Comté, France.In 2003, he joined the Laboratory of Electrical Systems and Environment (LSEE), Artois University, Béthune, France, as an Associate Professor and Researcher. His research interest is control of electrical systems and diagnosis of electrical machines.

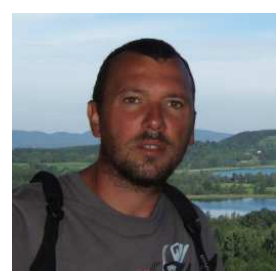

Eric Lefevre received, in 2001, the Ph.D. in physics from National Institute of Applied Sciences (INSA) of Rouen, France. He joined Univeristy of Artois in 2002, as associate professor. He obtained the French Research Habilitation (HDR) from Uniservity of Artois in 2012 and, as of 2013, he is full professor. His research interests include uncertainty modeling and information fusion with belief functions.

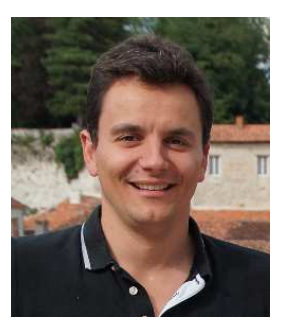

David Mercier received the $\mathrm{PhD}$ from the University of Technology of Compiègne (UTC), France, in 2006. Since September 2008, he is an Associate Professor at the University of Artois, France, after having been an Assistant Professor (French ATER) from September 2007 to August 2008. Since September 2012, he is an elected member of the executive board of the Belief Functions and Applications Society. He obtained his French Research Habilitation (HDR) from the University of Artois in 2015. His research interests include information fusion and reasoning with uncertainty in particular with belief functions.

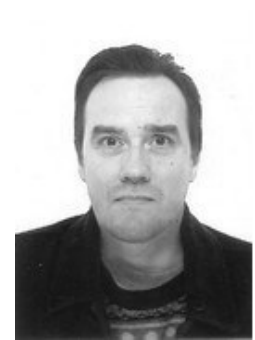

Raphaël Romary (M'10) received the Ph.D. from Lille University, Lille, France, in 1995 and the D. SC degree from Artois University, Béthune, France, in 2007. He is currently a Full Professor in Artois University and a Researcher at the Laboratory of Electrical Systems and Environment (LSEE). His research interest concerns the analytical modeling of electrical machines with applications to noise and vibration, losses, electromagnetic emissions, diagnosis.

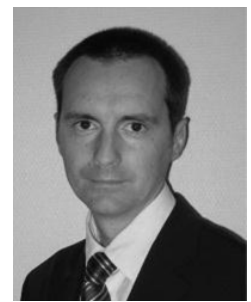

Cristian Demian received the $\mathrm{Ph}$. D from the University of Picardie Jules Verne Amiens, France, in 2005. He is currently Associate Professor at the Artois University and he joined the Electrical Systems and Environment Research Laboratory (LSEE), France. His research interests focus on diagnosis, modeling, efficiency, analysis and the reduction of noises and vibrations of electrical machines. 